\section{National survey of the technique of intravitreal triamcinolone injection in the United Kingdom}

Introduction

The indications for intravitreal triamcinolone acetonide (IVTA) have grown rapidly since popularized by Jonas. ${ }^{1}$ The optimal technique for IVTA is still in evolution. In the absence of clinical trials, the current practice is based on anecdotal reports, small case series, and personal preferences.

Although the complications of IVTA have been widely discussed in the literature, there are few papers that specifically address the technique of injection. There is no consensus among ophthalmologists about the optimal dose of triamcinolone acetonide. Recently, a group of ophthalmologists reviewed the current literature and produced guidelines for intravitreal injections. $^{2}$

This paper describes the current variations in the technique of IVTA in the United Kingdom.

\section{Methods}

In November 2004, a postal questionnaire (see Appendix A) was sent to all the 901 ophthalmologists in the United Kingdom who are on the Royal College of Ophthalmologists specialist register. The questions targeted specific areas of IVTA injection that are known to vary among published case series or might influence complications, for example infection. The average number of injections performed per month was classified according to the frequency. The questionnaires were returned in a prepaid self-addressed envelope. The data obtained were entered in a customized database and analysed using Microsoft Access 2000.
Keywords: intravitreal triamcinolone; psuedohypopyon; sterile endophthalmitis \begin{abstract}
or best practice administration. Published
descriptions of intravitreal steroid injectio techniques vary widely and variations are not evidence based. Observed UK practice is diverse. Eye (2007) 21, 480-486. doi:10.1038/sj.eye.6702232; published online 27 January 2006
\end{abstract}

2006

Proprietary interests: None

\section{Ophthalmology, Stoke \\ Aylesbury, \\ Department of \\ Stoke Mandeville Hospital, Mandeville Road, Aylesbury, HP21 7AL, UK \\ el: + 441296315000 ; \\ E-mail: shawfield@}

Received: 26 July 2005 Accepted in revised form: 20 November 2005 Published online: 27 January 


\section{Results}

There were 567 (63\%) returns by the 31st of January 2005. Five questionnaires were returned unanswered, as the addressee was no longer available at the address. Of the 562 valid replies, 139 (24.7\%) perform intravitreal triamcinolone injections regularly.

\section{Subspecialty (Figure 1)}

A total of $80.57 \%(n=112)$ of users were vitreoretinal (VR) or medical retina (MR) specialists. Table 1 shows the difference between MR specialists and VR surgeons in the practice of IVTA. Among the IVTA users, 27 described as 'Other' declared subspecialty interest in cornea and anterior segment $(n=8)$, cataract $(n=4)$, oculoplastics $(n=2)$, general ophthalmology $(n=1)$, paediatrics/neuro-ophthalmology/strabismus $(n=3)$, glaucoma $(n=1)$, and uveitis $(n=3)$. Five surgeons did not record their subspecialty interest.

\section{Frequency}

In all, $90 \%(n=125)$ of consultants who used IVTA perform less than five injections a month. Approximately

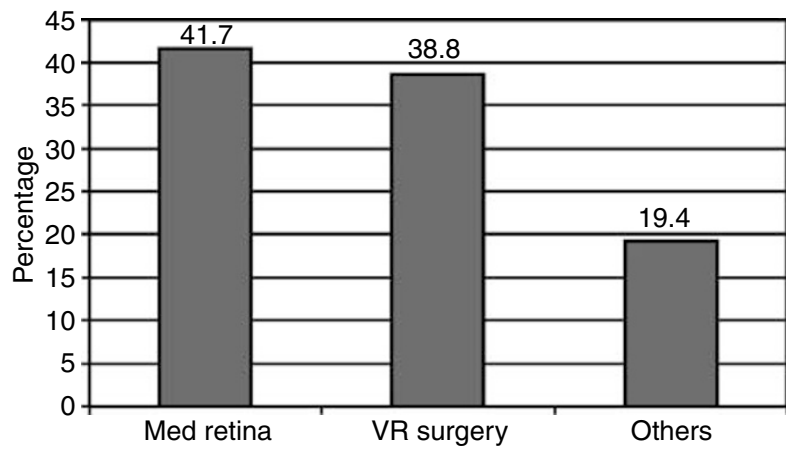

Figure 1 Intravitreal triamcinolone users and subspeciality.

Table 1 Comparison of medical retina and vitreoretinal specialists in performing intravitreal triamcinolone injection

\begin{tabular}{lcc}
\hline IVTA & $\begin{array}{c}\text { Medical retina } \\
(\mathrm{N}=58) \\
\text { (percentage) }\end{array}$ & $\begin{array}{c}\text { Vitreoretinal } \\
(\mathrm{N}=54) \\
\text { (percentage) }\end{array}$ \\
\hline Frequency of IVTA & & \\
$0-5$ & 84 & 93 \\
$5-10$ & 12 & 7 \\
Location, theatre & 67 & 89 \\
Dilatation of pupil & 74 & 87 \\
Iodine preparation of eye & 97 & 96 \\
Drape & 60 & 69 \\
Sterile surgical gown & 34 & 63 \\
Sterile gloves & 90 & 85 \\
\hline
\end{tabular}

9\% $(n=12)$ performed 5-10 injections per month and less than $2 \%(n=2)$ more than 10.

\section{IVTA preparation/technique}

Dose and volume

A total of $94 \%(n=130)$ of surgeons used $4 \mathrm{mg}$ of triamcinolone acetonide for intravitreal injection; $2 \%$ $(n=3)$ used $8 \mathrm{mg}$ and an equal number used $2 \mathrm{mg}$. Other doses included $10 \mathrm{mg}(n=1)$ and $20 \mathrm{mg}(n=1)$. One surgeon did not indicate the dose used. In all, $95 \%$ ( $n=132$ ) of surgeons used a volume of $0.1 \mathrm{ml}$ for injection with $5 \%$ of surgeons indicating using other volumes, which include $0.05 \mathrm{ml}(n=3)$ and $0.2 \mathrm{ml}(n=1)$. Three surgeons did not indicate the volume used.

\section{Preparation of steroid}

Among the surgeons, $84 \%(n=116)$ shook the commercial preparation before injection, $6.5 \%(n=9)$ aspirated the supernatant, and $5.8 \%(n=8)$ filtered the suspension. Two surgeons aspirated and filtered the suspension. One surgeon prepared the injection in the pharmacy. Three surgeons did not indicate the dose used.

\section{Needle size}

Among the surgeons, 54\% $(n=75)$ used $27 \mathrm{G}$ needle to perform the injection, whereas $21.58 \%(n=30)$ used $30 \mathrm{G}$, $9 \%(n=13)$ used $26 \mathrm{G}, 4 \%(n=6)$ used $25 \mathrm{G}$ needle, and $3 \%(n=4)$ used insulin syringe. In all, 3\% $(n=4)$ used other needles, which included 25 and $29 \mathrm{G}$. A total of $5 \%$ $(n=7)$ respondents have not indicated the size of needle.

\section{Location}

A total of $77 \%(n=106)$ preferred to inject intravitreal steroids in the operating theatre, whereas $19 \%(n=26)$ performed the injections in the outpatient department. In all, $4 \%(n=6)$ of the users performed injections either in the operating theatre or outpatient department. One surgeon did not indicate the location.

\section{Patient preparation}

Among the users, $78 \%(n=109)$ dilated the pupil before injection, 94\% $(n=131)$ prepared the eye with an iodine preparation, and $63 \%(n=88)$ draped the eye to be injected.

\section{Surgeon preparation}

Of the surgeons, $52 \%(n=67)$ donned a sterile gown during the injection and $86 \%(n=120)$ used sterile gloves to perform injections.

Anterior chamber (AC) paracentesis (Figures 2, $3 a$ and $b$ ) A total of $36 \%(n=50)$ of surgeons never performed paracentesis either pre or post injection. In all, $66 \%$ $(n=92)$ never performed paracentesis before injection. 


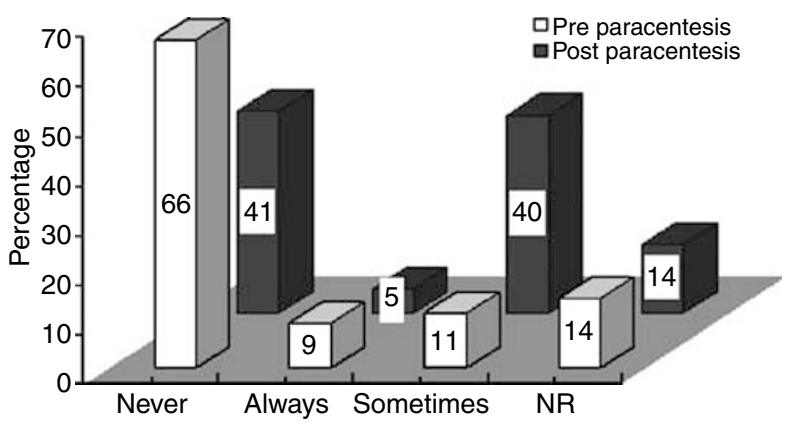

Figure 2 AC paracentesis before and after intravitreal injection (NR - not recorded).
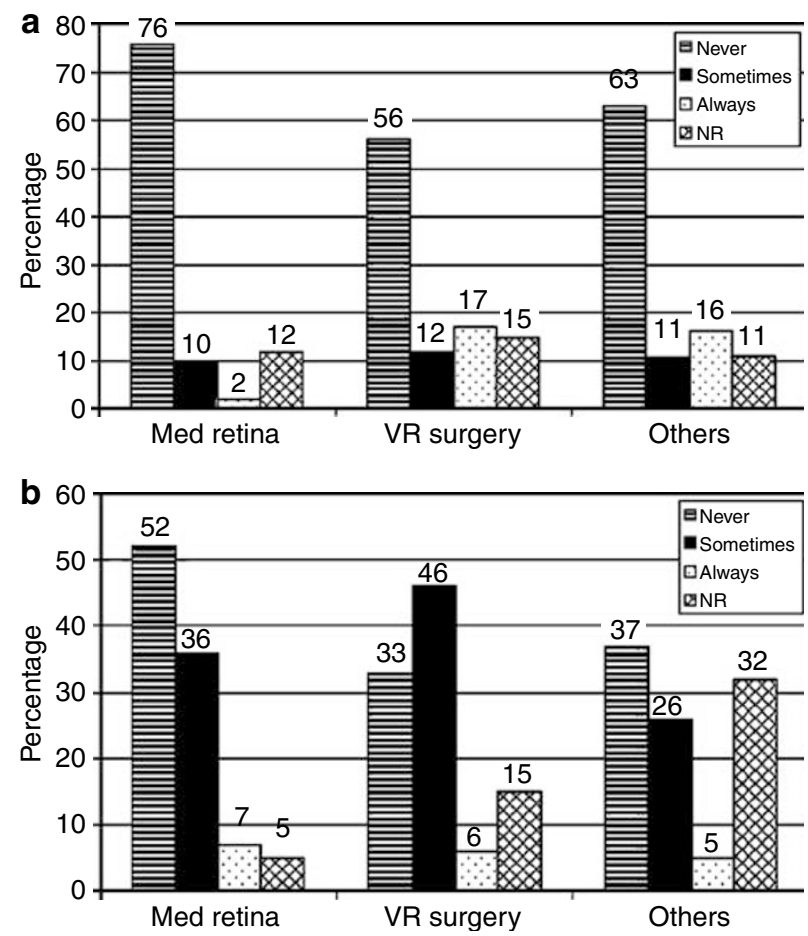

Figure 3 (a) Differences between medical retina specialists and VR surgeons in performing preinjection paracentesis (NR - not recorded). (b) Differences between medical retina specialists and VR surgeons in performing post injection paracentesis (NR - not recorded).

A total of $56 \%(n=30)$ of VR surgeons, and $76 \%(n=44)$ of MR specialists never performed paracentesis before injection. Among the surgeons, 41\% $(n=57)$ never performed paracentesis after the injection. The percentage of VR surgeons and MR specialists who never performed paracentesis after injection were $33 \%(n=18)$ \& 52\% ( $n=30)$, respectively.

A total of $9 \%(n=13)$ surgeons always performed paracentesis before injection. Of these, 69\% $(n=9)$ were VR surgeons and $8 \%(n=1)$ were MR specialists (Table 1$)$. In all, 5.7\% $(n=8)$ users always performed paracentesis after injection. Of these $38 \%(n=3)$ were VR surgeons and $50 \%(n=4)$ were MR specialists. Among the users, $11 \%(n=15)$ sometimes performed paracentesis before injection and $40 \%(n=55)$ sometimes performed paracentesis after injection.

\section{Postoperative management}

Postoperative drops

Among the users, 38\% $(n=53)$ did not use routine antibiotics after the injection, whereas a similar number (37\%) used topical chloramphenicol. Among the users, $3 \%(n=4)$ used topical quinolones after the injection. One surgeon used subconjunctival cefuroxime postinjection. In all, $24 \%(n=34)$ of users prescribed topical steroids after intravitreal triamcinolone injection. Of these, $70 \%(n=24)$ were steroid antibiotic combination. Eight users prescribed topical dexamethasone or betamethasone. Prednisolone acetate $1 \%(n=2)$ and ketorolac $(n=1)$ were other topical antiinflammatory drops used.

\section{Intraocular pressure (IOP) check}

A total of $26 \%(n=36)$ checked IOP on the same day, $23 \%$ $(n=32)$ the next day, and $33 \%(n=46)$ at the end of the first week. On the other hand, 9\% $(n=13)$ checked IOP after 2-4 weeks, and 9\% $(n=12)$ of users, did not indicate the time of first IOP check.

\section{Discussion}

Several case series have reported the effectiveness of intravitreal steroids in the treatment of proliferative diabetic retinopathy, ${ }^{3,4}$ diabetic macular oedema, ${ }^{1}$ ocular hypotony, ${ }^{5}$ macular oedema due to central retinal vein occlusion, ${ }^{6}$ uveitic cystoid macular oedema, ${ }^{7}$ and exudative macular degeneration. ${ }^{8}$ There is wide variation in the dose, preparation, technique, and postinjection care.

The commercially available preparation used for IVTA is Kenalog (Bristol Myers Squibb, Middlesex, UK). Kenalog is a suspension of triamcinolone acetonide granules in a suspending vehicle. The vehicle contains the suspending agents sodium carboxymethylcellulose and polysorbate 80 . The preservative is $1.5 \%$ benzylalcohol.

Whereas most authors report a dosage of 2 or $4 \mathrm{mg}^{7-9}$ Jonas et $a l^{10}$ report a dose of 20-25 mg of intravitreal triamcinolone. Marthides et $a l^{9}$ used $4 \mathrm{mg}$ of triamcinolone to achieve similar results as in Jonas' series, ${ }^{10}$ in the management of diabetic macular oedema. In our survey, $94 \%$ of the users used a dose of $4 \mathrm{mg}$ of triamcinolone in $0.1 \mathrm{ml}$. Although a dose of $4 \mathrm{mg}$ is readily available from the commercial preparation $(0.1 \mathrm{ml}$ of $40 \mathrm{mg} / \mathrm{ml}$ ), special preparation methods are required to prepare $25 \mathrm{mg}$ in $0.1 \mathrm{ml}$ to condense steroid crystals and remove the vehicle. 
The majority of users in our survey $(84 \%)$ use unmodified, shaken steroid, making no attempt to separate triamcinolone from the supernatant. Shaking allows uniform distribution of particles in suspension, thus avoiding supernatant vehicle alone being drawn into the syringe and thereby achieving a predictable dose. Hida et al ${ }^{11}$ report no ocular toxicity in rabbit eyes following injection of benzylalchohol in a dose similar to that available in the commercial preparation of triamcinolone. Recent toxicity studies ${ }^{12}$ with $0.025 \%$ benzyl alcohol (equivalent to $4 \mathrm{mg}$ of triamcinolone acetonide in $4 \mathrm{ml}$ of vitreous) in a retinal pigment epithelial cell culture found no significant reduction of cell viability compared with a control of balanced salt solution. However, the authors conclude that if the concentration of the vehicle had been increased further, a significant change in cell viability might have occurred.

Jonas et $\mathrm{al}^{13}$ argue that their filtering process decreases the risk of noninfectious endophthalmitis. RodriguezColeman et $a l^{14}$ evaluated the technique of filtering commercially available Kenalog as described by Jonas et al. ${ }^{10}$ Using high-performance liquid chromatography, the dose after filtration was found to range from 4.68 to $9.09 \mathrm{mg}$. Further, the benzyl alcohol concentration was similar irrespective of whether or not filter was used. Benzyl alcohol being lipophilic tends to partition in the triamcinolone fraction, thereby resulting in a higher concentration in a filtered preparation. Benzyl alcohol has been implicated in sterile endophthalmitis following intravitreal injections. ${ }^{15}$

The incidence of noninfectious endophthalmitis following IVTA injection has been reported to range from 0.2 to $6 \%{ }^{16-19}$ Noninfectious or sterile endophthalmitis may represent an acute inflammatory reaction to a component in the drug formulation and should be distinguished from pseudohypopyon - a collection of triamcinolone crystals, which have migrated to the AC. Moshifegi et $a l^{20}$ noted development of pseudohypopyon after 7 IVTA injections $(n=828)$. All cases developed within 3 days of injection and resolved without intervention within 2 weeks. Roth et $a l^{17}$ reported the incidence of pseudohypopyon to be $6.7 \%$. Jonas in his series of 520 injections reported one case of pseudohypopyon. ${ }^{19} \mathrm{AC}$ paracentesis of this patient demonstrated triamcinolone acetonide crystals and no evidence of infectious endophthalmitis. These reports suggest that pseudohypopyon after IVTA injections may be managed with close follow-up to rule out early endophthalmitis.

Infective endophthalmitis is the most devastating complication of IVTA. Moshfeggi et $a l^{21}$ describes eight cases of acute infectious endophthalmitis after 922 intravitreal triamcinolone injections. Jonas ${ }^{19}$ describes one case of infectious endophthalmitis in his series of 520 intravitreal triamcinolone injections. Reducing the risk of infection can be addressed by minimizing the bacterial flora present at the injection site and decreasing access of any bacteria through the injection site wound.

The survey found that $76 \%$ of surgeons performed IVTA in theatre. A total of $63 \%$ used a drape, $94 \%$ used iodine preparation, and $86 \%$ used gloves. It is interesting to note that the majority of surgeons in the UK perform IVTA in theatre. VR surgeons tend to use theatre slightly more than MR specialists (Table 1). With current high pressure on ophthalmologists to reduce cataract waiting times, it is unlikely that this is carried out for convenience, but rather because of the fear of introducing intraocular infection. It will be interesting to see whether the experience of clinical trials, such as the Macugen trial $^{22}$ where protocol does not dictate use of theatre, leads to more IVTA injections being performed outside theatre.

The size of the injection site wound depends primarily on needle size. Withdrawal of the needle after injection results in varying degrees of vitreous prolapse or 'vitreous wick', which may be an increased risk for intraocular infection. ${ }^{23}$ Factors producing vitreous wicks are elevated vitreous pressure during injection and a larger needle track through the sclera. A $30 \mathrm{G}$ needle may reduce the risk of vitreous incarceration but may clog with triamcinolone crystals, particularly if the steroid preparation has been filtered. Of the surgeons, $76 \%$ used a needle that is $27 \mathrm{G}$ or smaller. This is in accordance with the guidelines laid down by Aiello et al. It is interesting to note the technique of misaligning the conjunctival and scleral entry sites by moving the needle sideways after penetrating the conjunctiva before entering the eye, as described for $25 \mathrm{G}$ vitrectomy, ${ }^{24}$ to reduce the possibility of externalizing any vitreous wick.

Among the surgeons who perform IVTA in the UK, $58 \%$ prescribe topical antibiotics postoperatively. This is compatible with guidelines for IVTA that recommend use of post injection topical antibiotics for 3 days. $^{2}$ Although there is no direct evidence for using antibiotics to prevent endophthalmitis, as the epithelial defence of eye is breached during IVTA, bacterial invasion is possible. In all, $24 \%(n=34)$ prescribed topical steroid preparation. There is no evidence supporting the use of topical steroids after intravitreal injection.

The need to perform AC paracentesis for IVTA is debatable. Injection as small as $0.1 \mathrm{ml}$ can increase the intravitreal pressure significantly because of increase in vitreous volume. The duration is usually short lived. The highest pressure will be immediately after injection and excessive pressure can be avoided by preinjection paracentesis. Among the surgeons, in the survey, 20\% $(n=28)$ indicated that they either always or sometimes perform preinjection AC paracentesis. While this avoids the immediate IOP spike, and may decrease the risk of 'vitreous wick', it may not be always indicated and is not 
without risk. It is interesting to note that $17 \%$ of VR surgeons perform preinjection paracentesis compared to $2 \%$ of MR specialists.

There was a tendency within our respondents to perform AC paracentesis after IVTA injection only when required. Among the surgeons, 45\% perform paracentesis post-IVTA 'always' or 'sometimes' compared with only $20 \%$ of surgeons performing paracentesis pre-IVTA. These surgeons comment that they would perform AC paracentesis if there were either evidence of reduced central retinal artery (CRA) perfusion, loss of light perception, or if the eyeball was hard. This conforms to the recommendations by Aiello et $a l^{2}$ who suggest pupillary dilatation for viewing CRA. Moshfeghi et al, ${ }^{21}$ in their series of 922 intravitreal injections of triamcinolone, performed AC paracenteses as required guided by CRA perfusion. However, Aiello et $a l^{2}$ in their guidelines for intravitreal triamcinolone injection suggest avoiding routine prophylactic or postinjection paracentesis.

Later onset rise in IOP was shown in $43.8 \%$ of eyes in the Intravitreal Triamcinolone Study ${ }^{25}$ which used a dose of $4 \mathrm{mg}$ triamcinolone in $0.1 \mathrm{ml}$. The effect was transient, noted 1-2 months after the injections and controlled adequately by topical antiglaucoma medications. The IOP elevation lasted for a mean period of 6 months. There was no statistically significant rise in IOP reported within the first week.

Wingate $e t a l^{26}$ reported elevation of IOP by $5 \mathrm{mmHg}$ or higher in $32 \%$ of eyes that received single injection of triamcinolone acetonide. Jonas, in his series of 75 eyes treated with $25 \mathrm{mg}$ of triamcinolone acetonide in $0.2 \mathrm{ml}$, found IOP rise higher than $21 \mathrm{mmHg}$ in $52 \%$ of eyes. ${ }^{27}$ In another small series by Marthides et $a l,{ }^{9}$ where patients received $4 \mathrm{mg}$ of triamcinolone acetonide in $0.1 \mathrm{ml}, 34.6 \%$ of eyes developed IOP of $21 \mathrm{mmHg}$ or higher. These studies suggest that intravitreal steroid is likely to raise IOP significantly in up to half of the injected eyes. This rise is transient, lasting for 6-9 months and is not seen before 1 week. Hence, an IOP check 1-week postinjection followed by regular follow-up for the next few months is appropriate. In our survey, 33\% have the first IOP check at 1 week but $59 \%$ of users check IOP on the same or next day.

In the absence of randomized controlled trials, the best practice should be based on logical considerations. Aiello et $a l^{2}$ systematically review the current evidence, where available, for each component of the IVTA injection technique. In Table 2 we have compared the practice among UK surgeons with the recommendations laid down by Aiello et al. ${ }^{2}$ With more intravitreal injections being used for the delivery of both triamcinolone and Macugen, ${ }^{22}$ the workload for retinal specialists is increasing. It is hoped that further evolution in technique will be based on evidence to reduce complications rather than convenience of meeting this higher demand.
Table 2 Comparison of UK practice in performing intravitreal triamcinolone injection with guidelines by Aiello et al

\begin{tabular}{lcl}
\hline IVTA & $\begin{array}{c}\text { UK practice } \\
\text { (Percentage) }\end{array}$ & Aiello et al ${ }^{2}$ guidelines \\
\hline Gloves & 86 & Appropriate \\
Drape & 63 & Not essential \\
Iodine & 94 & Recommended \\
Pupil dilatation & 78 & $\begin{array}{l}\text { Preferred } \\
\text { Needle size (27 or 30 G) }\end{array}$ \\
& 70 & $\begin{array}{l}\text { Recommend '27 G } \\
\text { or smaller' }\end{array}$ \\
Postinjection antibiotics & 58 & 'Own discretion' \\
& & (for 72 h or less) \\
AC paracentesis & & Avoid \\
$\quad$ Pre (always) & 9 & Avoid \\
Post (always) & 6 & \\
\hline
\end{tabular}

\section{References}

1 Jonas JB, Sofker A. Intraocular injection of crystalline cortisone as an adjunctive treatment of diabetic macular oedema. Am J Ophthalmol 2001; 132: 425-427.

2 Aiello PL, Brucker JA, Chang S, Cunningham Jr ET, D' Amico DJ, Flynn Jr HW et al. Evolving guidelines for intravitreous injections. Retina 2004; S3-S19.

3 Jonas JB, Hayler JK, Panda- Jonas S. Intravitreal injection of crystalline cortisone as adjunctive treatment of proliferative vitreoretinopathy. Br J Ophthalmol 2000; 84: 1064-1067.

4 Jonas JB, Hayler JK, Sofker A, Panda-Jonas S. Intravitreal injection of crystalline cortisone as adjunctive treatment of proliferative diabetic retinopathy. Am J Ophthalmol 2001; 131: 468-471.

5 Jonas JB, Hayler JK, Panda- Jonas S. Intravitreal injection of crystalline cortisone as treatment of pre-phthisical ocular hypotony. Graef Arch Clin Exp Ophthalmol 2001; 239: 464-465.

6 Greenberg PB, Marthidis A, Rogers AH, Duker JS, Reichel E. Intravitreal triamcinolone acetonide for macular oedema due to central retinal vein occlusion. Br J Ophthalmol 2002; 86: 247-248.

7 Antcliff RJ, Spalton DJ, Stanford MR, Graham EM, Ffytche TJ, Marshall J. Intravitreal triamcinolone for uveitic cystoid macular oedema: an optical coherence tomography study. Ophthalmology 2001; 108: 765-772.

8 Danis RP, Thomas A, Ciulla TA, Pratt LM, Anilekar W. Intravitreal triamcinolone acetonide in exudative age related macular degeneration. Retina 2000; 20: 244-250.

9 Martidis A, Duker JS, Greenberg PB, Rogers AH, Puliafito $\mathrm{CA}$, Reichel $\mathrm{E}$ et al. Intravitreal triamcinolone for refractory diabetic macular oedema. Ophthalmology 2002; 109: 920-927.

10 Jonas JB, Kreissig I, Sofker A, Degenring RF. Intravitreal injection of triamcinolone for diffuse diabetic macular oedema. Arch Ophthalmol 2003; 121(1): 57-61.

11 Hida T, Chandler D, Arena JE, Marchemer R. Experimental and clinical observations of the intraocular toxicity of commercial corticosteroid preparations. Am J Ophthalmol 1986; 101: 190-195.

12 Yeung CK, Chan KP, Chan CK, Pang CP, Lam DS. The cytotoxicity of triamcinolone on cultured human retinal pigment epithelial cells: comparison with dexamethasone and hydrocortisone. Jpn J Ophthalmol 2004; 48(3): 236-242.

13 Jonas JB, Degenring RF, Kreissig I. Intravitreal injection of triamcinolone for diffuse macular oedema - in reply. Arch Ophthalmol 2004; 122: 1086-1088. 
14 Rodriguez-Coleman H, Yuan P, Kim H, Gravlin L, Srivastava S, Csaky KG et al. Intravitreal injection of triamcinolone for diffuse macular oedema. Arch Ophthalmol 2004; 122: 1085-1086.

15 Young ML, Kaiser PK, Sears JE. Acute endophthalmitis following intravitreal triamcinolone acetonide injection (abstract). In: Program and Abstracts of the American Academy of Ophthalmology 2002 Meeting. Orlando, FL, October 20-23, 2002.

16 Sutter FK, Gilles MC. Psuedo-endophthalmitis after intravitreal injection of triamcinolone. Br J Ophthalmol 2003; 87: 972-974.

17 Roth DB, Chieh J, Spirn MJ, Green SN, Yarian DL, Chaudhry NA et al. Non- infectious endophthalmitis associated with intravitreal triamcinolone injection. Arch Ophthalmol 2003; 121: $1279-1282$.

18 Nelson ML, Tennant MT, Sivalingam A, Regillo CD, Belmont JB, Martidis A et al. Infectious and presumed noninfectious endophthalmitis after intravitreal triamcinolone acetonide injection. Retina 2003; 23(5): 686-691.

19 Jonas JB, Kreissig I, Degenring RF. Endophthalmitis after intravitreal injection of triamcinolone acetonide. Arch Ophthalmol 2003; 121: 1663-1664.

20 Moshfeghi AA, Scott IU, Flynn Jr HW, Puliafito CA. Psuedohypopyon after intravitreal triamcinolone acetonide injection for cystoid macular edema. Am J Ophthalmol 2004; 138(3): 489-492.

21 Moshfegi DM, Kaiser PK, Scott IU, Sears JE, Benz M, Sinesterra JP et al. Acute endophthalmitis following intravitreal triamcinolone acetonide injection. Am J Ophthalmol 2003; 136: 791-796.

22 Gragoudas ES, Adamis AP, Cunnigham Jr ET, Feinsod M, Guyer DR et al. Pegaptanib for neovascular age-related macular degeneration. N Engl J Med 2004; 30; 351(27): 2805-2816.

23 Chen SDM, Mohammed Q, Bowling B, Patel CK. Vitreous wick syndrome - a potential cause of endophthalmitis after intravitreal injection of triamcinolone through the pars plana. Am J Ophthalmol 2004; 137(6): 1159-1160.

24 Ibarra MS, Hermel M, Prenner JL, Hassan TS et al. Longerterm outcomes of transconjunctival sutureless 25-gauge vitrectomy. Am J Ophthalmol 2005; 139(5): 831-836.

25 Gillies MC, Simpson JM, Billson FA, Luo W, Penfold P, Chua W et al. Safety of intravitreal injection of triamcinolone. Arch Ophthalmol 2004; 122: 336-340.

26 Wingate RJ, Beaumont PE. Intravitreal triamcinolone and elevated intraocular pressure. Aust NZ J Ophthalmol 1999; 27: 431-432.

27 Jonas JB, Kreissig I, Degenring RF. Intraocular pressure after intravitreal injection of triamcinolone acetonide. $\mathrm{Br} \mathrm{J}$ Ophthalmol 2003; 87: 24-27.

\section{Appendix A: Questionnaire}

National survey of intravitreal triamcinolone injection technique

\section{Appendix: Questionnaire}

National Survey of Intravitreal Triamcinolone Injection Technique

What is your sub specialty?

VR Surgery $\square$ Medical Retina $\square$ Other

How many times per month do you use intravitreal triamcinolone?

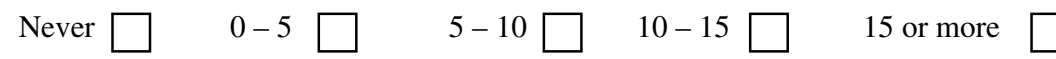

If applicable, please describe your standard technique for intravitreal triamcinolone injection

1. Steroid prep "I do not filter. I shake the vial prior to drawing up steroid"

"I remove carrier fluid by-" Filtration $\square$ and/or aspiration

Other

2. Dose

3. Where

4. Patient prep ${ }^{\mathrm{n}}$

5. $\underline{\text { Surgeon prep }}{ }^{\mathrm{n}}$

$$
4 \mathrm{mg} \text { in } 0.1 \mathrm{ml}
$$

OPD $\square$ Theatre

Dilate pupil

Drape
Other

Other

Iodine $(5$ or $10 \%)$

Chlorhexidine 
6. Needle

$30 \mathrm{G}$
(Yellow) $27 \mathrm{G}$
(Grey) $\underset{\text { (Brown) }}{26 \mathrm{G}} \longrightarrow$ other.....

7. Injection Site Phakic.

Pseudophakic

Aphakic.

8. $\underline{\text { AC paracentesis }}$ Pre-injection Always $\square$ Never $\square$ Sometimes Post injection Always $\square$ Never $\square$ Sometimes

If you answered "sometimes", what factors influence your use and/or timing of AC paracentesis?

8. Post op drops Duration

9. $\mathbf{1}^{\text {st IOP check }}$ Same day Next day 1 Week Other...

What other details of your technique do you feel are important? 